\title{
Commentary
}

\section{Genomic instability as a major mechanism for acquired resistance to EGFR tyrosine kinase inhibitors in cancer}

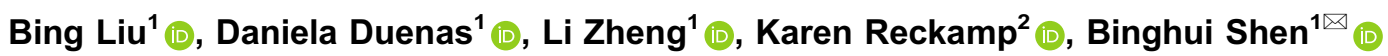 \\ ${ }^{1}$ Department of Cancer Genetics and Epigenetics, Beckman Research Institute of City of Hope, 1500 East Duarte Road, \\ Duarte, CA 91010, USA \\ 2 Division of Medical Oncology, Cedars-Sinai Medical Center, 8700 Beverly Blvd, West Hollywood, CA 90048, USA \\ $\triangle$ Correspondence: bshen@coh.org (B. Shen) \\ Accepted May 8, 2021
}

The mutation-mediated overexpression of epidermal growth factor receptor tyrosine kinase (EGFR TK) and its activation play an important role in the cellular proliferation and epithelial tumorigenesis. A series of inhibitors targeting the intracellular tyrosine kinase (TK) domain of EGFR have been developed and applied to clinical practice. Although these inhibitors safely and effectively restrain tumor cell proliferation and prolong survival in some patients, acquired resistance ultimately arises. DNA mutations contribute to druginduced cancer-cell resistance. Genomic instability, especially DNA replication and repair error, provides the major source for DNA mutations. Identifying the central mechanisms underlying the generation and selection of resistance mutations may provide critical opportunities for novel regimens in combating drug resistance. In this review, we provide an overview of EGFR tyrosine kinase inhibitors (TKls) in non-small cell lung carcinoma (NSCLC) treatment and their challenges. We also discuss the major source of genomic instability in TKI resistance and hypothesize that the maintenance of DNA replication and repair machinery might be used to develop novel treatment regimens for patients with NSCLC.

EGFR is a member of the receptor tyrosine kinase (RTK) family (Lemmon et al., 2014). The activation of cytosol membrane EGFR via binding EGF-like ligands initiates receptor dimerization, phosphorylation of its own tyrosine residues, and activation of downstream signaling pathways. Aberrant EGFR activation, due to its single-nucleotide substitutions in exons 18-21, in-frame duplications/insertions in exon 20 , or short in-frame deletions in exon 19 , can amplify a series of downstream pro-oncogenic signaling pathways including JAK/STAT, PI3K/AKT/mTOR, PLC/PKC/NFKB and MEK/ERK. These pathways aim to support and benefit cancer cell survival, proliferation and tissue differentiation
(El-Hashim et al., 2017) (Fig. 1). Three generations of EGFR TKIs have been developed to specifically target EGFR mutations to the kinase domain in NSCLC. However, an ever-increasing number of mutation-mediated resistances are inevitable (Zhang, 2016b).

Due to the mutation-mediated destabilization of the EGFR TK domain, abnormal activation of EGFR constitutively propagates EGFR TK activity and downstream pro-oncogenic signaling pathways to drive cancer cell survival and proliferation. Moreover, the expressions and interactions of a vast amount of genes and proteins are significantly changed during EGFR activation, suggesting the profound and extensive role of EGFRs involvement in the diverse signaling networks of cells (Waters et al., 2012). Although there are various pharmaceutical agents that target the proteins involved in the EGFR-mediated network of NSCLC, EGFR TKI remain the first line of treatment (Dong et al., 2021). Activated EGFR can promote protein nuclear translocation or redistribute to the nucleus via autophosphorylation, where it functions in DNA replication and repair which is an important process for genome fidelity (Wang et al., 2010, 2012). Reduced EGFR TK activity in response to TKIs might impair DNA replication and repair processes and boost the production of mutations for cancer progression. Both preexisting and de novo generation of genome wide mutations have been observed in vivo and in vitro, suggesting the EGFR TKIs initiate genomic instability to generate and select for mutations that confer resistance to their inhibition of cancer cell growth and induction of apoptosis (Hata et al., 2016). Therefore, a better understanding of how TKIs initiate genomic instability is critical for developing novel strategies to control NSCLC progression.

Three generations of EGFR TKIs, as the ATP mimetic inhibitors, have been developed so far to target the most common somatic EGFR mutations, including the exon 19 


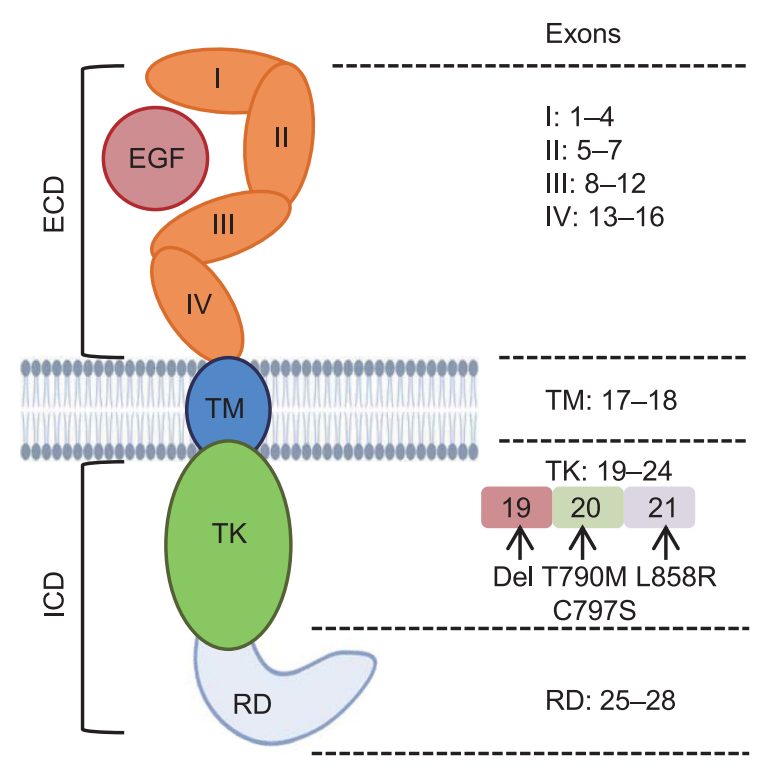

Figure 1. The EGFR protein structure and corresponding gene exons. Exons 1-16 encode extracellular domains I-IV (orange) which can form the ligand interaction conformation. Exons 17-18 encode the transmembrane domain (blue) for connecting extracellular domains and intracellular domains. Exons 19-24 encode tyrosine kinase domain. Exon 19 deletion and exon $21 \mathrm{~L} 858 \mathrm{R}$ mutation are original mutations that cause constant activation of tyrosine kinase activity in non-small cell lung carcinoma. Exon $20 \mathrm{~T} 790 \mathrm{M}$ is the dominant secondary mutation acquired in response to the 1st and 2nd generation TKIs, while exon 20 C797s mutation is the secondary mutation acquired in response to the 3rd generation TKI osimertinib. Exon 25-28 encode C-terminal phosphorylation domain which mediates the interactions between the receptor and downstream substrates upon receptor activation. Abbreviations: EGF, epidermal growth factor; ECD, extracellular domain; TM, transmembrane; ICD, intracellular domain; TK, tyrosine kinase; RD, regulatory/phosphorylation domain.

deletion and the L858 mutation in exon 21, which account for more than $85 \%$ of all EGFR mutations (Molina-Vila et al., 2009) (Table 1). The first-generation TKIs, including gefitinib and erlotinib, reversibly bind to the active site of the EGFR TK domain to prevent ATP binding for kinase activity transduction. Acquired resistance to first-generation TKIs most often arises due to the T790M mutation, occurring in around $50 \%$ of patients (Ma et al., 2011). Despite difficulties in the detection of pre-existing mutations, pre-treatment sample evaluations have been reported to harbor T790M mutations (Watanabe et al., 2015). Furthermore, using a T790M-negative in vitro system, it was also demonstrated that EGFR TKI treatment can generate T790M mutations de novo (Kim et al., 2012). Specifically, a study conducted by Kadi and colleagues, found that NFKB activation by TKIs promotes activation-induced cytidine deaminase (AICDA) expression, which leads to the deamination of 5-methylcytosine to thymine and finally generates the T790M mutation (EI Kadi et al., 2018). Second-generation TKIs, including afatinib and dacomitinib, irreversibly bind to the mutated and wild-type EGFR, as well as the receptors from bypass signaling pathways, such as HER2 (Genova et al., 2014; Baraibar et al., 2020), to provide a more sustained and potent EGFR inhibitory function. However, the acquired mutations including T790M still occur over the course of treatment. Recently, the mutant-selective third generation TKI osimertinib was designed to selectively and covalently bind to the C797 residue of EGFR at the ATP-binding pocket edge of its TK domain to repress EGFR-activating mutations while sparing wild-type receptors (Greig, 2016). Previously, osimertinib was used as second-line treatment in NSCLC patients who developed T790M-mediated resistance to first- and secondgeneration TKIs (Zhang, 2016a). Recent studies suggested that it was more effective to use osimertinib as first-line therapy (Aguilar-Serra et al., 2019). However, the most common mutation, C797S in exon 20 , has been observed in around $10-26 \%$ of patients with resistance to second-line osimertinib treatment and around $7 \%$ of patients with resistance to first-line treatment (Mehlman et al., 2019).

In addition to EGFR-dependent mutations, an array of alternative EGFR-independent bypass signaling pathways may be concurrently activated to exacerbate tumor heterogeneity and therapeutic difficulty under EGFR-TKI treatment. Thus, the combination strategies which target both oncogenic mutations of EGFR and EGFR-independent bypass signaling pathways have been applied to delay the acquisition of resistance to some extent in many cases. The most common mechanism for bypass signaling-mediated acquired resistance, in $5 \%-50 \%$ of patients receiving second-line osimertinib treatment and $7 \%-15 \%$ of patients receiving first-line osimertinib treatment, occurs due to high levels of MET gene amplification (Ou et al., 2016). The MET gene amplification can induce constitutive activation of the EGFR downstream pro-oncogenic signaling pathways, such as JAK/STAT, PI3K/AKT/mTOR, PLC/PKC/NFKB and MEK/ ERK pathways (Rotow et al., 2020; Yu et al., 2021). Thus, MET inhibitors have been used in combination with osimertinib to overcome acquired resistance (Awad et al., 2019). Another common bypass alteration is the overexpression of Anexelekto $(A X L)$, a tyrosine kinase receptor, which can interact with EGFR and has been reported to be associated with poor osimertinib responses (Taniguchi et al., 2019). The combination of $A X L$ inhibitor cabozantinib with osimertinib is a promising strategy to prolong osimertinib sensitivity (Reckamp et al., 2019). However, clinical trials are needed to confirm the long-term response for these strategies in patients. Beyond these EGFR-dependent and independent alterations to chromosomal DNA, there are yet other routes promoting drug resistance at the genomic level. For example, extrachromosomal DNA (ecDNA), which can be unevenly segregated into daughter cells due to the lack of a centromere, has been found in nearly half of human cancers (Turner et al., 2017). It has been reported that mutant EGFR 
Table 1. Summary of key EGFR-TK inhibitors

\begin{tabular}{|c|c|c|c|c|c|c|c|}
\hline & EGFR-TKIs & $\begin{array}{l}\text { Trade } \\
\text { name }\end{array}$ & $\begin{array}{l}\text { Primary } \\
\text { target }\end{array}$ & $\begin{array}{l}\text { Mechanism } \\
\text { of action }\end{array}$ & $\begin{array}{l}\text { Dominant } \\
\text { secondary } \\
\text { mutation }\end{array}$ & $\begin{array}{l}\text { Clinical trial } \\
\text { number }\end{array}$ & Refs \\
\hline \multirow[t]{4}{*}{$\begin{array}{l}\text { First } \\
\text { generation }\end{array}$} & Gefitinib & Iressa & EGFR & Reversible & T790M & NCT02959749 & $\begin{array}{l}\text { Muhsin et al. } \\
(2003)\end{array}$ \\
\hline & Erlotinib & Tarceva & EGFR & Reversible & T790M & NCT00364351 & $\begin{array}{l}\text { Bareschino } \\
\text { et al. } \\
(2007)\end{array}$ \\
\hline & Lapatinib & Tyverb & $\begin{array}{l}\text { EGFR; } \\
\text { ErbB2 }\end{array}$ & Reversible & T790M & NCT01125566 & $\begin{array}{l}\text { Moy et al. } \\
\text { (2007) }\end{array}$ \\
\hline & Icotinib & Conmana & EGFR & Reversible & T790M & NCT03231501 & $\begin{array}{l}\text { Shi et al. } \\
\text { (2013) }\end{array}$ \\
\hline \multirow[t]{3}{*}{$\begin{array}{l}\text { Second } \\
\text { generation }\end{array}$} & Afatinib & Gilotrif & $\begin{array}{c}\text { EGFR; } \\
\text { ErbB2; } \\
\text { ErbB4 }\end{array}$ & Irreversible & T790M & NCT02094573 & $\begin{array}{l}\text { Dungo and } \\
\text { Keating } \\
(2013)\end{array}$ \\
\hline & Dacomitinib & Vizimpro & $\begin{array}{c}\text { EGFR; } \\
\text { ErbB2; } \\
\text { ErbB4 }\end{array}$ & Irreversible & T790M & NCT01000025 & $\begin{array}{l}\text { Wu et al. } \\
(2017)\end{array}$ \\
\hline & Neratinib & Nerlynx & $\begin{array}{c}\text { EGFR; } \\
\text { ErbB2; } \\
\text { ErbB4 }\end{array}$ & Irreversible & T790M & NCT01000025 & $\begin{array}{l}\text { Sequist } \\
(2010)\end{array}$ \\
\hline $\begin{array}{l}\text { Third } \\
\text { generation }\end{array}$ & Osimertinib & Tagrisso & $\begin{array}{l}\text { EGFR } \\
\text { T790M }\end{array}$ & Irreversible & C797S & NCT01449461 & Greig (2016) \\
\hline
\end{tabular}

ecDNA is eliminated in tumor cells during TKI treatment, inducing drug resistance, but restores after drug withdrawal (Nathanson et al., 2014).

How do spontaneous somatic mutations originate, particularly under the stresses such as drug administration? A series of repair processes coordinate with DNA replication to reduce spontaneous mutagenesis and maintain DNA fidelity. The key determinant of DNA fidelity depends on DNA polymerases selectivity and proof reading functions, which are important in organized incorporation of nucleotides into DNA during replication (Ludmann and Marx, 2016; Bębenek and Ziuzia-Graczyk, 2018; Xing et al., 2019). Moreover, during the DNA synthesis in lagging strand, the DNA polymerases, such as Pola and primase, de novo synthesize the RNA primer and $\alpha$-segment with high error rates. Elimination of those errors relies on the structure-specific nucleases, such as FEN1 and DNA2, which are involved in the accurate RNA primer removal and the editing of $\alpha$-segment errors. Deficiency in these processes will not only leave in those errors, but also generate duplication mutations due to failure of RNA primer removal which then exacerbates the mutation burden (Zheng and Shen, 2011; Li et al., 2018; Zheng et al., 2020). The mismatch repair (MMR) signaling is another determinant of DNA replication fidelity by correcting the remaining mismatches after DNA replication to promise DNA fidelity under homeostasis (Haradhvala et al., 2018). However, EGFR TKIs might hijack the key DNA replication/repair components and impair these processes for promoting single tumor cells to acquire multi-level molecular alterations at the genetic, transcriptional, post-translational, and epigenetic levels and ultimately boost intrinsic tumor heterogeneity for genome wide mutation generation (Majem and Remon, 2013).

It is established now that EGFR TK possesses more than 200 substrates (https://www.phosphosite.org/homeAction. action; https://string-db.org/network/9606.ENSP00000275493). These protein substrates are not only components of oncogenic signaling pathways (JAK/STAT, PI3K/AKT/mTOR, PLC/PKC/NFKB and MEK/ERK) that promote cancer cell survival and proliferation, but are also involved in DNA replication machinery (Fig. 2). Although EGFR inhibition with TKIs may suppress pro-oncogenic pathways, it may also result in other unintended effects such as the impairment of DNA replication fidelity and promotion of somatic mutagenesis. Supporting evidence is available for such a hypothesis. Cao and colleagues have recently demonstrated that the expression of heat shock protein 70 (HSP70), an ATP-dependent molecular chaperone, is reduced by EGFR TKI treatment (Cao et al., 2018). They found that HSP70 physically interacts with multiple enzymes in base excision repair (BER) and DNA replication pathways. Thus, the down regulation of HSP70 in response to TKIs enhances the gene mutation rate and attenuates BER to facilitate acquired resistance. Activated EGFR from the cytosol membrane can redistribute to the nucleus via the Golgi and endoplasmic reticulum (ER) under the assistance of translocon (Wang and Hung, 2009). Nuclear EGFR plays an essential role in stabilization of DNA replication and repair proteins, such as proliferation cell nuclear antigen (PCNA). PCNA recruits and 


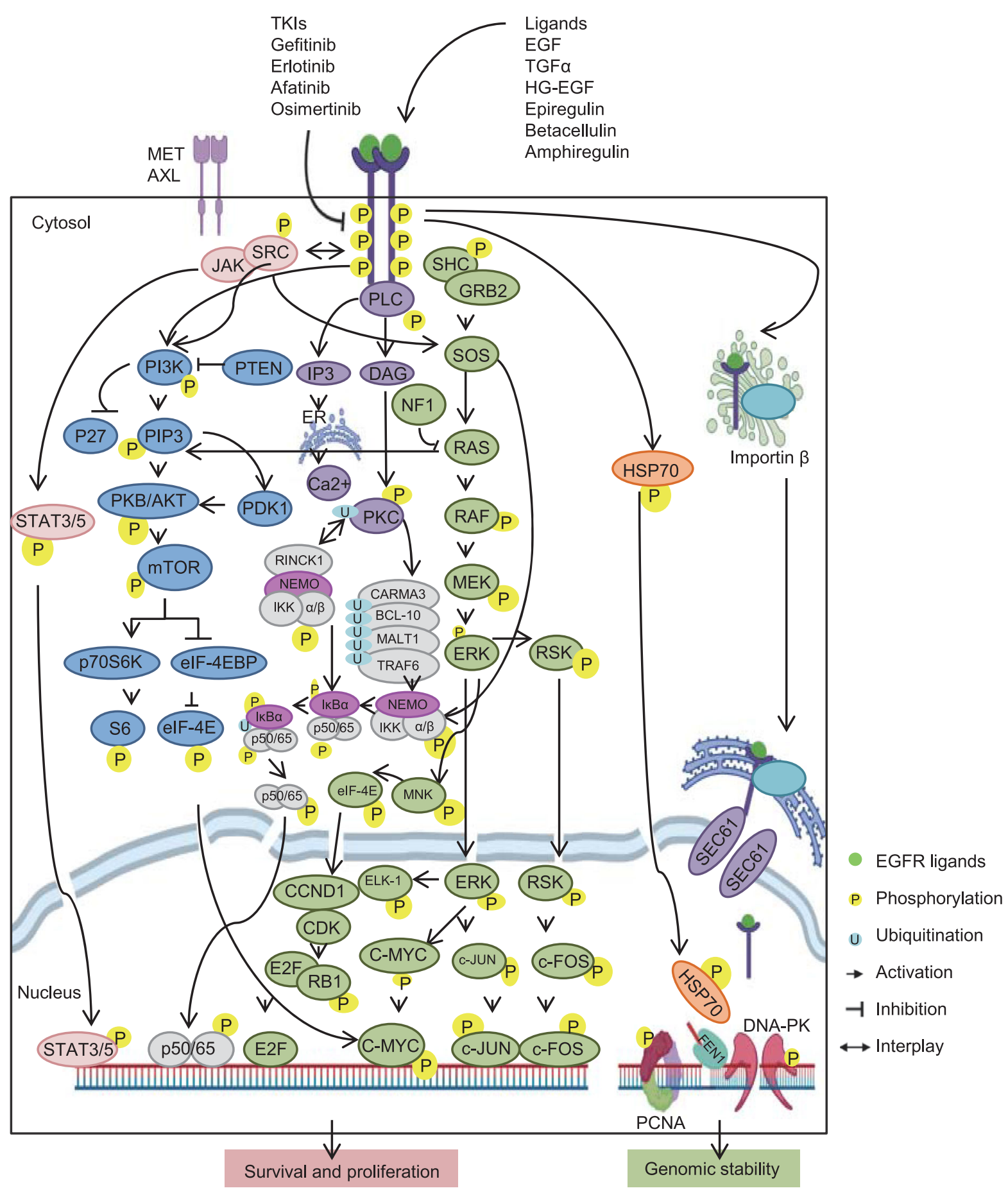


Figure 2. The network of EGFR-dependent phosphorylation cascade. This network is created based on KEGG database and current literatures. The EGFR ligands, such as EGF, TGFa, HG-EGF, Epiregulin, Betacellulin, and Amphiregulin, interact with EGFR extracellular domain to activate it via inducing its TK domain trans-autophosphorylation. The other kinases, such as SRC, are also able to phosphorylate EGFR from cytosol and be phosphorylated by activated EGFR in reverse. The expression of a number of genes is significantly changed during EGFR activation, which is accompanied with the various dynamic modifications, particularly phosphorylation. The most characterized pro-oncogenic signaling pathways phosphorylated and activated upon EGFR activation are listed at the left, including JAK/STAT, PI3K/AKT/mTOR, PLC/PKC/NFKB and MEK/ERK signaling pathways. The downstream transcription factors, including STAT3/5, p50/p65 NFKB dimer, E2F, c-MYC and c-JUN/c-FOS, play the oncogenic function to benefit cancer cell survival and proliferation. Furthermore, the stabilities of DNA replication and repair proteins, which are controlled by EGFR activation and nuclear EGFR, are illustrated at the right, including HSP70, PCNA and DNA-PK. Inhibition of EGFR TK activity with TKIs not only blocks pro-oncogenic pathways, but also DNA replication and repair pathways which are important for maintaining genomic stability. Genomic instability is the major source for resistance mutation generation, which might reduce EGFR TKI efficiency and activate the receptors from bypass signaling pathways, such as MET and AXL receptors, to further support cancer progression. Thus, maintaining genomic stability, especially by protecting the expression and stability of DNA replication and repair components, may forestall the generation and evolution of tumor cell mutations, ultimately reducing drug resistance. Abbreviations: SRC, Protooncogene tyrosine-protein kinase Src; JAK, Janus kinase; STAT3/5, Signal transducer and activator of transcription3/5; PI3K, Phosphatidylinositol-4,5-bisphosphate 3-kinase; PTEN, Phosphatase and tensin homolog; PIP3, Phosphatidylinositol (3,4,5)trisphosphate; PDK, 3-phosphoinositide-dependent protein kinase; PKB, Protein kinase B; AKT, v-Akt murine thymoma viral oncogene homolog; mTOR, Mechanistic target of rapamycin kinase; p70S6K, Ribosomal protein S6 kinase; elF-4EBP, Eukaryotic translation initiation factor 4E binding protein; EIF4E, Eukaryotic translation initiation factor 4E; S6, Ribosomal protein S6; PLC, Phospholipase C; IP3, Inositol trisphosphate; DAG, Diacylglycerol; PKC, Protein kinase C; RINCK1, E3 ligase RING finger protein that interacts with $C$ kinase 1; NEMO, Inhibitor of nuclear factor kappa B kinase regulatory subunit gamma; IKK, inhibitor of nuclear factor kappa B kinase subunit; CARMA3, Caspase recruitment domain family member 10; BCL-10, B cell lymphoma protein 10; MALT1, Mucosa-associated lymphoid tissue lymphoma translocation gene 1; TRAF6, TNF receptor associated factor 6; p50, NFKB Subunit 1; p65, RELA proto-oncogene, NFKB subunit; SHC, SHC adaptor protein 1; GRB2, Growth factor receptor bound protein 2; SOS, Ras/Rac guanine nucleotide exchange factor; RAS, Rat sarcoma virus; RAF, Rapidly accelerated fibrosarcoma; MEK, Mitogenactivated protein kinase kinase; ERK, Extracellular signal-regulated kinase; RSK, MAP kinase-activated protein kinase; MNK, ATPase copper transporting alpha; CCND1, Cyclin D1; CDK, Cyclin dependent kinase; E2F, E2F transcription factor; RB1, RB transcriptional corepressor 1; ELK-1, ETS transcription factor; c-MYC, Myc proto-oncogene protein; C-JUN, Transcription factor AP-1; C-FOS, AP-1 transcription factor subunit; HSP70, Heat shock $70 \mathrm{kDa}$ protein; SEC61, Translocon subunit alpha 1; PCNA, Proliferation cell nuclear antigen; DNA-PK, DNA-dependent protein kinase; FEN1, Flap endonuclease 1; ER, Endoplasmic reticulum.

coordinates DNA synthesis machinery to ensure accurate DNA replication and repair at the replication forks (Moldovan et al., 2007). Nuclear EGFR mediates the phosphorylation of PCNA in its chromatin-bound form, which is important for maintenance of PCNA stability and protection of chromatinbound PCNA from proteasome-dependent degradation via lysine polyubiquitination (Wang et al., 2006; Lo et al., 2012). Blockage of its phosphorylation by EGFR TKIs may impair the assembly of the replication and repair machinery and lead to genome instability. The other important example is DNA-dependent protein kinase (DNA-PK) which is required for rejoining double-strand breaks to repair DNA. The nuclear EGFR can physically interact with DNA-PK and trigger DNA-PK phosphorylation (Bandyopadhyay et al. 1998; Dittmann et al., 2005a). Impaired DNA-PK phosphorylation due to the blockage of EGFR nuclear translocation reduces DNA-PK activity and promotes DNA damage (Dittmann et al., 2005b, 2008). These pieces of evidence suggest that EGFR TKIs may not cause DNA damage directly but can impair DNA replication and repair machinery due to degradation of the component proteins that missing phosphorylation protection and then lead to the acquired genome wide mutations.

Mimicking the therapeutic approach of the HIV "cocktail" regimens, the recently approved combination therapeutic regimen with the $3^{\text {rd }}$ generation EGFR TKI osimertinib and MET inhibitor Tepotinib is based on the observation that MET gene amplification bypasses the EGFR TK activity and upregulates the EGFR downstream pro-oncogenic signaling pathway in EGFR TKI-treated patients (Markham, 2020). The combinations of EGFR-TKIs with immune checkpoint inhibitors are an emerging trend in NSCLC treatment (Jin et al., 2020). The immune checkpoint inhibitors include the ones for the programmed cell death-1 receptor and its ligand (PD-1/PD-L1) and cytotoxic T-lymphocyte-associated antigen 4 (CTLA-4) (Johnson et al., 2014). However, these regimens do not include a strategy to minimize the mutations from its origin. Our proposal for a therapeutic avenue is to protect the integrity of the DNA replication machinery and to suppress the S-phase cell cycle checkpoint activation in order to avoid drug-induced mutations. To maintain DNA replication fidelity, the employment of a proteasome inhibitor 
in combination with EGFR-TKI therapies may preserve DNA replication protein stability and should be considered. As previously mentioned, HSP70 is susceptible to proteasome degradation in response to EGFR TKIs. Recent experiments in our laboratory showed that when administering a protease inhibitor, Bortezomib, there is a clear reduction of HSP70 degradation. Furthermore, after conducting cellular based assays we observed a significant improvement to EGFR TKI sensitivity as well. A vast majority of the somatic mutations are generated through error prone DNA synthesis including aberrant Okazaki fragment maturation in the S-phase cells, which requires extended S-phase time and activation of the checkpoints. Combining the checkpoint inhibitors, such as ATR inhibitors, with TKIs, to reduce the acquired resistance is an alternative proposed strategy (Vendetti et al., 2015). In summary, EGFR serves a multifaceted role in cells and its inhibition can prove deleterious effects to genome stability. As we continue to face the persistent challenge of drug resistance in EGFR TKls, we turn our focus to maintaining the integrity of DNA replication and repair pathways. By conserving the fidelity of the DNA replication and repair machinery we may increase drug sensitivity and impede tumor cell mutations that aid in the acquisition of drug resistance.

\section{AUTHOR CONTRIBUTIONS}

$\mathrm{BL}$ conceived and wrote the manuscript; DD, LZ, and KR contributed to the manuscript editing. BHS conceived and supervised the project and wrote the manuscript.

\section{ABBREVIATIONS}

AICDA, activation-induced cytidine deaminase; $A X L$, anexelekto; BER, base excision repair; CTLA-4, cytotoxic T-lymphocyteassociated antigen 4; DNA-PK, DNA-dependent protein kinase; ecDNA, extrachromosomal DNA; EGFR, epidermal growth factor receptor; ER, endoplasmic reticulum; HSP70, heat shock protein 70; MMR, mismatch repair; NSCLC, non-small cell lung carcinoma; RTK, receptor tyrosine kinase; TK, tyrosine kinase; TKIs, tyrosine kinase inhibitors; PD-1/PD-L1, programmed cell death-1 receptor and its ligand; PCNA, proliferating cell nuclear antigen.

\section{FUNDING}

This work was supported by the National Institutes of Health [R01CA073764 to B.H.S., R50CA211397 to L.Z.].

\section{CONFLICT OF INTEREST}

The authors declare no conflict of interest.

\section{OPEN ACCESS}

This article is licensed under a Creative Commons Attribution 4.0 International License, which permits use, sharing, adaptation, distribution and reproduction in any medium or format, as long as you give appropriate credit to the original author(s) and the source, provide a link to the Creative Commons licence, and indicate if changes were made. The images or other third party material in this article are included in the article's Creative Commons licence, unless indicated otherwise in a credit line to the material. If material is not included in the article's Creative Commons licence and your intended use is not permitted by statutory regulation or exceeds the permitted use, you will need to obtain permission directly from the copyright holder. To view a copy of this licence, visit http:// creativecommons.org/licenses/by/4.0/.

\section{REFERENCES}

Aguilar-Serra J, Gimeno-Ballester V, Pastor-Clerigues A, Milara J, Marti-Bonmati E, Trigo-VicenteC Alós-Almiñana M, Cortijo J (2019) Osimertinib in first-line treatment of advanced EGFRmutated non-small-cell lung cancer: a cost-effectiveness analysis. J Comp Eff Res 8(11):853-863

Awad MM, Leonardi GC, Kravets S, Dahlberg SE, Drilon A, Noonan SA, Camidge DR, Ou SI, Costa DB, Gadgeel SM et al (2019) Impact of MET inhibitors on survival among patients with nonsmall cell lung cancer harboring MET exon 14 mutations: a retrospective analysis. Lung Cancer 133:96-102

Bandyopadhyay D, Mandal M, Adam L, Mendelsohn J, Kumar R (1998) Physical interaction between epidermal growth factor receptor and DNA-dependent protein kinase in mammalian cells. J Biol Chem 273(3):1568-1573

Baraibar I, Mezquita L, Gil-Bazo I, Planchard D (2020) Novel drugs targeting EGFR and HER2 exon 20 mutations in metastatic NSCLC. Crit Rev Oncol Hematol 148:102906

Bareschino MA, Schettino C, Troiani T, Martinelli E, Morgillo F, Ciardiello $F$ (2007) Erlotinib in cancer treatment. Ann Oncol 18 (Suppl 6):vi35-vi41

Bębenek A, Ziuzia-Graczyk I (2018) Fidelity of DNA replication-a matter of proofreading. Curr Genet 64(5):985-996

Cao X, Zhou Y, Sun H, Xu M, Bi X, Zhao Z, Shen B, Wan F, Hong Z, Lan $L$ et al (2018) EGFR-TKI-induced HSP70 degradation and BER suppression facilitate the occurrence of the EGFR T790 M resistant mutation in lung cancer cells. Cancer Lett 424:84-96

Dittmann K, Mayer C, Fehrenbacher B, Schaller M, Raju U, Milas L, Chen DJ, Kehlbach R, Rodemann HP (2005a) Radiation-induced epidermal growth factor receptor nuclear import is linked to activation of DNA-dependent protein kinase. J Biol Chem 280 (35):31182-31189

Dittmann K, Mayer C, Rodemann HP (2005b) Inhibition of radiationinduced EGFR nuclear import by C225 (Cetuximab) suppresses DNA-PK activity. Radiother Oncol 76(2):157-161

Dittmann K, Mayer C, Kehlbach R, Rodemann HP (2008) Radiationinduced caveolin-1 associated EGFR internalization is linked with nuclear EGFR transport and activation of DNA-PK. Mol Cancer 7:69

Dong RF, Zhu ML, Liu MM, Xu YT, Yuan LL, Bian J, Xia YZ, Kong LY (2021) EGFR mutation mediates resistance to EGFR tyrosine kinase inhibitors in NSCLC: from molecular mechanisms to clinical research. Pharmacol Res 167:105583 
Dungo RT, Keating GM (2013) Afatinib: first global approval. Drugs 73(13):1503-1515

El Kadi N, Wang L, Davis A, Korkaya H, Cooke A, Vadnala V, Brown NA, Betz BL, Cascalho M, Kalemkerian GP et al (2018) The EGFR T790M mutation is acquired through AICDA-mediated deamination of 5-methylcytosine following TKI treatment in lung cancer. Cancer Res 78(24):6728-6735

El-Hashim AZ, Khajah MA, Renno WM, Babyson RS, Uddin M, Benter IF, Ezeamuzie C, Akhtar S (2017) Src-dependent EGFR transactivation regulates lung inflammation via downstream signaling involving ERK1/2, PI3Kס/Akt and NFKB induction in a murine asthma model. Sci Rep 7(1):9919

Genova C, Rijavec E, Barletta G, Burrafato G, Biello F, Dal Bello MG, Coco S, Truini A, Alama A, Boccardo F et al (2014) Afatinib for the treatment of advanced non-small-cell lung cancer. Expert Opin Pharmacother 15(6):889-903

Greig SL (2016) Osimertinib: first global approval. Drugs 76(2):263273

Haradhvala NJ, Kim J, Maruvka YE, Polak P, Rosebrock D, Livitz D, Hess JM, Leshchiner I, Kamburov A, Mouw KW et al (2018) Distinct mutational signatures characterize concurrent loss of polymerase proofreading and mismatch repair. Nat Commun 9 (1):1746

Hata AN, Niederst MJ, Archibald HL, Gomez-Caraballo M, Siddiqui FM, Mulvey HE, Maruvka YE, Ji F, Bhang HE, Krishnamurthy Radhakrishna $V$ et al (2016) Tumor cells can follow distinct evolutionary paths to become resistant to epidermal growth factor receptor inhibition. Nat Med 22(3):262-269

Jin R, Zhao J, Xia L, Li Q, Li W, Peng L, Xia Y (2020) Application of immune checkpoint inhibitors in EGFR-mutant non-small-cell lung cancer: from bed to bench. Ther Adv Med Oncol 12:1758835920930333

Johnson DB, Rioth MJ, Horn L (2014) Immune checkpoint inhibitors in NSCLC. Curr Treat Options Oncol 15(4):658-669

Kim Y, Ko J, Cui Z, Abolhoda A, Ahn JS, Ou SH, Ahn MJ, Park K (2012) The EGFR T790M mutation in acquired resistance to an irreversible second-generation EGFR inhibitor. Mol Cancer Ther 11(3):784-791

Lemmon MA, Schlessinger J, Ferguson KM (2014) The EGFR family: not so prototypical receptor tyrosine kinases. Cold Spring Harb Perspect Biol 6(4):a020768

Li Z, Liu B, Jin W, Wu X, Zhou M, Liu VZ, Goel A, Shen Z, Zheng L, Shen B (2018) hDNA2 Nuclease/helicase promotes centromeric DNA replication and genome stability. EMBO J 37(14)

Lo YH, Ho PC, Wang SC (2012) Epidermal growth factor receptor protects proliferating cell nuclear antigen from cullin $4 \mathrm{~A}$ proteinmediated proteolysis. J Biol Chem 287(32):27148-27157

Ludmann S, Marx A (2016) Getting it right: how DNA polymerases select the right nucleotide. Chimia (Aarau) 70(3):203-206

Ma C, Wei S, Song Y (2011) T790M and acquired resistance of EGFR TKI: a literature review of clinical reports. J Thorac Dis 3 (1):10-18

Majem M, Remon J (2013) Tumor heterogeneity: evolution through space and time in EGFR mutant non small cell lung cancer patients. Transl Lung Cancer Res 2(3):226-237

Markham A (2020) Tepotinib: first approval. Drugs 80(8):829-833
Mehlman C, Cadranel J, Rousseau-Bussac G, Lacave R, Pujals A, Girard N, Callens C, Gounant V, Théou-Anton N, Friard S et al (2019) Resistance mechanisms to osimertinib in EGFR-mutated advanced non-small-cell lung cancer: a multicentric retrospective French study. Lung Cancer 137:149-156

Moldovan GL, Pfander B, Jentsch S (2007) PCNA, the maestro of the replication fork. Cell 129(4):665-679

Molina-Vila MA, Bertran-Alamillo J, Mayo C, Rosell R (2009) Screening for EGFR mutations in lung cancer. Discov Med 8 (43):181-184

Moy B, Kirkpatrick P, Kar S, Goss P (2007) Lapatinib. Nat Rev Drug Discov 6(6):431-432

Muhsin M, Graham J, Kirkpatrick P (2003) Gefitinib. Nat Rev Drug Discov 2(7):515-516

Nathanson DA, Gini B, Mottahedeh J, Visnyei K, Koga T, Gomez G, Eskin A, Hwang K, Wang J, Masui K et al (2014) Targeted therapy resistance mediated by dynamic regulation of extrachromosomal mutant EGFR DNA. Science 343(6166):72-76

Ou SI, Agarwal N, Ali SM (2016) High MET amplification level as a resistance mechanism to osimertinib (AZD9291) in a patient that symptomatically responded to crizotinib treatment post-osimertinib progression. Lung Cancer 98:59-61

Reckamp KL, Frankel PH, Ruel N, Mack PC, Gitlitz BJ, Li T, Koczywas M, Gadgeel SM, Cristea MC, Belani CP et al (2019) Phase II trial of cabozantinib plus erlotinib in patients with advanced epidermal growth factor receptor (EGFR)-mutant nonsmall cell lung cancer with progressive disease on epidermal growth factor receptor tyrosine kinase inhibitor therapy: a california cancer consortium phase II trial $(\mathrm{NCl}$ 9303). Front Oncol 9:132

Rotow JK, Gui P, Wu W, Raymond VM, Lanman RB, Kaye FJ, Peled N, Fece de la Cruz F, Nadres B, Corcoran RB et al (2020) Cooccurring alterations in the RAS-MAPK pathway limit response to MET inhibitor treatment in MET Exon 14 skipping mutationpositive lung cancer. Clin Cancer Res 26(2):439-449

Sequist LV, Besse B, Lynch TJ, Miller VA, Wong KK, Gitlitz B, Eaton K, Zacharchuk C, Freyman A, Powell C et al (2010) Neratinib, an irreversible pan-ErbB receptor tyrosine kinase inhibitor: results of a phase II trial in patients with advanced non-small-cell lung cancer. J Clin Oncol 28(18):3076-3083

Shi Y, Zhang L, Liu X, Zhou C, Zhang S, Wang D, Li Q, Qin S, Hu C, Zhang $Y$ et al (2013) Icotinib versus gefitinib in previously treated advanced non-small-cell lung cancer (ICOGEN): a randomised, double-blind phase 3 non-inferiority trial. Lancet Oncol 14 (10):953-961

Taniguchi H, Yamada T, Wang R, Tanimura K, Adachi Y, Nishiyama A, Tanimoto A, Takeuchi S, Araujo LH, Boroni M et al (2019) AXL confers intrinsic resistance to osimertinib and advances the emergence of tolerant cells. Nat Commun 10(1):259

Turner KM, Deshpande V, Beyter D, Koga T, Rusert J, Lee C, Li B, Arden K, Ren B, Nathanson DA et al (2017) Extrachromosomal oncogene amplification drives tumour evolution and genetic heterogeneity. Nature 543(7643):122-125

Vendetti FP, Lau A, Schamus S, Conrads TP, O'Connor MJ, Bakkenist CJ (2015) The orally active and bioavailable ATR kinase inhibitor AZD6738 potentiates the anti-tumor effects of 
cisplatin to resolve ATM-deficient non-small cell lung cancer in vivo. Oncotarget 6(42):44289-44305

Wang SC, Hung MC (2009) Nuclear translocation of the epidermal growth factor receptor family membrane tyrosine kinase receptors. Clin Cancer Res 15(21):6484-6489

Wang SC, Nakajima Y, Yu YL, Xia W, Chen CT, Yang CC, McIntush EW, Li LY, Hawke DH, Kobayashi R et al (2006) Tyrosine phosphorylation controls PCNA function through protein stability. Nat Cell Biol 8(12):1359-1368

Wang YN, Lee HH, Lee HJ, Du Y, Yamaguchi H, Hung MC (2012) Membrane-bound trafficking regulates nuclear transport of integral epidermal growth factor receptor (EGFR) and ErbB-2. J Biol Chem 287(20):16869-16879

Wang YN, Wang H, Yamaguchi H, Lee HJ, Lee HH, Hung MC (2010) COPI-mediated retrograde trafficking from the Golgi to the ER regulates EGFR nuclear transport. Biochem Biophys Res Commun 399(4):498-504

Watanabe M, Kawaguchi T, Isa S, Ando M, Tamiya A, Kubo A, Saka H, Takeo S, Adachi H, Tagawa T et al (2015) Ultra-sensitive detection of the pretreatment EGFR T790M mutation in non-small cell lung cancer patients with an EGFR-activating mutation using droplet digital PCR. Clin Cancer Res 21(15):3552-3560

Waters KM, Liu T, Quesenberry RD, Willse AR, Bandyopadhyay S, Kathmann LE, Weber TJ, Smith RD, Wiley HS, Thrall BD (2012) Network analysis of epidermal growth factor signaling using integrated genomic, proteomic and phosphorylation data. PLoS ONE 7(3):e34515

Wu YL, Cheng Y, Zhou X, Lee KH, Nakagawa K, Niho S, Tsuji F, Linke R, Rosell R, Corral J et al (2017) Dacomitinib versus gefitinib as first-line treatment for patients with EGFR-mutation-positive nonsmall-cell lung cancer (ARCHER 1050): a randomised, open-label, phase 3 trial. Lancet Oncol 18(11):1454-1466

Xing X, Kane DP, Bulock CR, Moore EA, Sharma S, Chabes A, Shcherbakova PV (2019) A recurrent cancer-associated substitution in DNA polymerase $\varepsilon$ produces a hyperactive enzyme. Nat Commun 10(1):374

Yu D, Zhao W, Vallega KA, Sun SY (2021) Managing acquired resistance to third-generation EGFR tyrosine kinase inhibitors through co-targeting MEK/ERK signaling. Lung Cancer (Auckl) 12:1-10

Zhang H (2016a) Osimertinib making a breakthrough in lung cancer targeted therapy. Onco Targets Ther 9:5489-5493

Zhang $\mathrm{H}$ (2016b) Three generations of epidermal growth factor receptor tyrosine kinase inhibitors developed to revolutionize the therapy of lung cancer. Drug Des Devel Ther 10:3867-3872

Zheng L, Shen B (2011) Okazaki fragment maturation: nucleases take centre stage. J Mol Cell Biol 3(1):23-30

Zheng L, Meng Y, Campbell JL, Shen B (2020) Multiple roles of DNA2 nuclease/helicase in DNA metabolism, genome stability and human diseases. Nucleic Acids Res 48(1):16-35 